\title{
THE SHANGHAI PASTEUR INSTITUTE.
}

\author{
By ARTHUR STANLEY, M.D., B.S. Lond., D.P.H. \\ Health Officer of Shanghai.
}

THE idea of having the means of applying the Anti-rabic treatment of Pasteur in Shanghai, China, had its origin in the marked incidence of rabies among the numerous dogs of the Shanghai district and the consequent large mortality from this disease. The local condition was the more marked because of the short incubation period observed in Shanghai both in the human subject and in the rabbit inoculated from the rabid dog, being seldom much over a month in man and rarely over two weeks in rabbits inoculated subdurally.

As the Shanghai laboratory was the first in British hands to offer to the public the advantages of Pasteur's treatment it may prove interesting to describe the beginnings of this institution as a part of the work of the Health Department of the Shanghai Municipal Council. Notwithstanding the comparative isolation of Shanghai from Western civilisation an efficient Public Health Service has been organised as a necessary branch of the local government of the foreign settlement. This includes a well equipped laboratory affording every facility for original investigation.

In 1898 after making inoculations in the Shanghai laboratory of rabbits from dogs suspected of rabies, I worked at Kitasato's laboratory in Tokio, Japan, receiving there myself the anti-rabic inoculation for prophylactic purposes and procuring the brain of a rabbit, preserved in glycerin, which had died of the intensive virus of rabies, with which to commence the series in Shanghai. On returning to my own laboratory I inoculated two rabbits subdurally with this virus (then fourteen days old) but obtained no result and even after several trials it proved innocuous ${ }^{1}$. Another source of virus was therefore sought. Dr Simond,

1 It is possible that the glycerine used for preserving the brain may have been impure or the different breed of rabbits used may have had something to do with it-the animals used by Kitasato being immense creatures with curly hair, while the Shanghai rabbits were mostly small albinos bred in the laboratory, aged about three months and scarcely weighing more than one kilo. 
the Director of the Saigon Pasteur Institute, kindly sent me in February 1899 the brain of a rabbit, which had died sixteen days previously, the incubation period having been seven days. The brain was preserved in glycerin in a sealed tube. At about the same time another brain from a rabbit presenting symptoms of rabies on the seventh day and dying on the tenth day was received through the post from Kitasato in Tokio. Both of these brains proved effective and the series (1) from the Saigon Pasteur Institute, (2) from Kitasato's laboratory in Tokio, after a preliminary lengthening of the incubation period to the ninth day or thereabouts assumed one varying between six and eight days.

\section{TABLE I.}

Showing the identity of incubation period and duration of the disease in rabbits inoculated with intensive virus of rabies from two distinct sources.

The figures relate to the first 24 rabbits inoculated of each series.

\begin{tabular}{|c|c|c|c|c|}
\hline \multirow{2}{*}{$\begin{array}{l}\text { Rabbit } \\
\text { No. }\end{array}$} & \multicolumn{2}{|c|}{ Virus-Kitasato (Tokio) } & \multicolumn{2}{|c|}{ Virus-Simond (Saigon) } \\
\hline & $\begin{array}{l}\text { Incubation in } \\
\text { days }\end{array}$ & Day of death & $\begin{array}{c}\text { Incubation in } \\
\text { days }\end{array}$ & Day of death \\
\hline 1 & 9 & 13 & 9 & 13 \\
\hline 2 & 10 & 15 & 9 & 12 \\
\hline 3 & 8 & 11 & 8 & 10 \\
\hline 4 & 8 & 10 & 8 & 10 \\
\hline 5 & 7 & 12 & 7 & 10 \\
\hline 6 & 11 & 14 & 8 & 10 \\
\hline 7 & 7 & 10 & 8 & 12 \\
\hline 8 & 8 & 10 & 8 & 10 \\
\hline 9 & 7 & 9 & 16 & 19 \\
\hline 10 & 10 & 14 & 8 & 11 \\
\hline 11 & 10 & 15 & 7 & 9 \\
\hline 12 & 9 & 10 & 8 & 13 \\
\hline 13 & 8 & 10 & 8 & 14 \\
\hline 14 & 8 & 12 & 6 & 11 \\
\hline 15 & 7 & 11 & 7 & 10 \\
\hline 16 & 7 & 10 & 7 & 12 \\
\hline 17 & 7 & 11 & 7 & 11 \\
\hline 18 & 12 & 17 & 6 & 9 \\
\hline 19 & 7 & 11 & 7 & 11 \\
\hline 20 & 7 & 11 & 7 & 10 \\
\hline 21 & 7 & 12 & 7 & 13 \\
\hline 22 & 8 & 12 & 8 & 12 \\
\hline 23 & 7 & 10 & 7 & 12 \\
\hline 24 & 6 & 9 & 7 & 13 \\
\hline Average & $8 \cdot 1$ & $11 \cdot 6$ & $7 \cdot 8$ & $11 \cdot 6$ \\
\hline
\end{tabular}


It will be seen from the tables that the incubation and day of death average out much the same.

TABLE II.

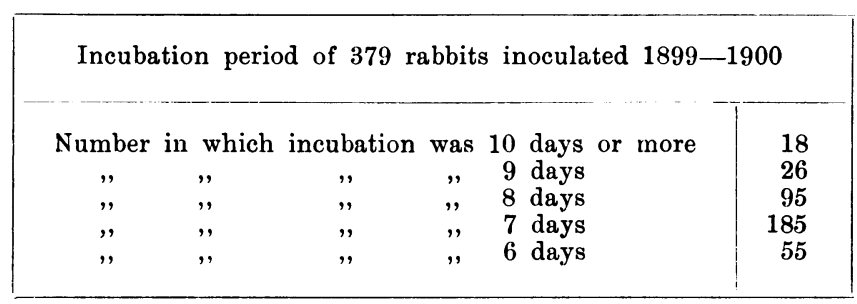

TABLE III.

\begin{tabular}{|c|c|}
\hline $\begin{array}{r}\text { Duration of syn } \\
\text { inoculat }\end{array}$ & rabhits \\
\hline $\begin{array}{ll}6 & \text { days } \\
5 & , \\
4 & , \\
3 & , \\
2 & , \\
1 & ,\end{array}$ & $\begin{array}{r}12 \\
36 \\
45 \\
123 \\
137 \\
26\end{array}$ \\
\hline
\end{tabular}

Two rabbits after manifesting symptoms of rabies recovered.

The Shanghai Pasteur Institute after six months' preparation was opened to the public for treatment in March 1899 and the series has been continuously maintained, some 379 rabbits having been inoculated.

Up to the present date seventeen persons have received the treatment, including five for prophylactic purposes. In six the dog which caused the bite was proved rabid by inoculation in the laboratory. In one the dog died of undoubted rabies certified by a qualified veterinary surgeon. In five the dogs were not heard of after the bite, so that there was only presumptive evidence of rabies. Among those treated there were two deaths, one from undoubted rabies 33 days after the bite and another presumably from rabies (the case was not seen by a medical man) 27 days after the bite, but it is a significant fact that in each of these cases the treatment had been interrupted; in one case the patient (a Chinese) not presenting himself for treatment for five days and in the other, on account of alcoholism, for one day during the 


\section{A. Stanley}

treatment. Moreover these were the only two of the seventeen in which the treatment had been interrupted. The history of these two cases is as follows:

Case I. A Swedish Policeman was bitten slightly in the wrist while attempting to catch a dog. The animal was subsequently shot, though not suspected of rabies. On account of its having bitten the man a rabbit was inoculated from the dog. The rabbit presented symptoms of rabies on the 12th day and died on the 16th day. The man began the simple Pasteur treatment on the day following the bite, beginning with the cord dried 14 days and diminishing one each day up to a cord dried three days. The man got drunk and did not come for treatment on the 12th day. The treatment lasted 20 days, the latter part consisting of a repetition of cords dried five, four and three days respectively. He presented symptoms of hydrophobia exactly one month after the bite and died two days afterwards, 33 days after receiving the bite.

Case II. A Chinese small boy was bitten through the nose by a dog whose brain inoculated into rabbits produced rabies after an incubation period of 13 days. The intensive treatment was given, a cord as strong as the seventh day of drying being injected on the fourth day of treatment. The child did not come for treatment from the 11th to the 17th day. The treatment lasted 22 days including the five days during which the treatment was interrupted, the strongest cord given having dried three days. The child is reported to have died 27 days after the bite. It was not seen by a medical man, but as the child appeared well when I last saw him five days previously, it is probable that he died of hydrophobia having a remarkably short incubation.

The comparative fewness of cases receiving the Pasteur treatment in Shanghai is explained by the prejudice of the Chinese against Western Medicine. However, five Chinese received the anti-rabic injections, including four of my Chinese laboratory assistants.

\section{Methods employed at the Shanghai Pasteur Institute.}

The method used in the Shanghai laboratory is modified by the comparative scarcity of cases setking treatment. In order to reduce the manipulations and the animals used, to an effective minimum, it has been found that one rabbit developing rabies every second day, suffices for a descending series of dried cords beginning on any given odd or even day, as follows: 
TABLE IV.

Method used for obtaining a series of diried cords with a minimum of rabbits inoculated.

\begin{tabular}{|c|c|c|c|c|c|c|c|c|c|c|c|c|c|}
\hline $\begin{array}{l}\text { Day of } \\
\text { month }\end{array}$ & \multicolumn{13}{|c|}{ No. of days of drying of cord } \\
\hline 1 & 1 & & & & & & & & & & & & \\
\hline 2 & 2 & & & & & & & & & & & & \\
\hline 3 & 3 & 1 & & & & & & & & & & & \\
\hline 4 & 4 & 2 & & & & & & & & & & & \\
\hline 5 & 5 & 3 & 1 & & & & & & & & & & \\
\hline 6 & 6 & 4 & 2 & & & & & & & & & & \\
\hline 7 & 7 & 5 & 3 & 1 & & & & & & & & & \\
\hline 8 & 8 & 6 & 4 & 2 & & & & & & & & & \\
\hline 9 & 9 & 7 & 5 & 3 & 1 & & & & & & & & \\
\hline 10 & 10 & 8 & 6 & 4 & 2 & & & & & & & & \\
\hline 11 & 11 & 9 & 7 & 5 & 3 & 1 & & & & & & & \\
\hline 12 & 12 & 10 & 8 & 6 & 4 & 2 & & & & & & & \\
\hline 13 & 13 & 11 & 9 & 7 & 5 & 3 & 1 & & & & & & \\
\hline 14 & 14 & 12 & 10 & 8 & 6 & 4 & 2 & & & & & & \\
\hline 15 & & 13 & 11 & 9 & 7 & 5 & 3 & 1 & & & & & \\
\hline 16 & & 14 & 12 & 10 & 8 & 6 & 4 & 2 & & & & & \\
\hline 17 & & & 13 & 11 & 9 & 7 & 5 & 3 & 1 & & & & \\
\hline 18 & & & 14 & 12 & 10 & 8 & 6 & 4 & 2 & & & & \\
\hline 19 & & & & 13 & 11 & 9 & 7 & 5 & 3 & 1 & & & \\
\hline 20 & & & & 14 & 12 & 10 & 8 & 6 & 4 & 2 & & & \\
\hline 21 & $\ldots$ & & $\ldots$ & $\ldots$ & .13 & 11 & $\boldsymbol{\theta}$ & 7 & 5 & 3 & 1 & & \\
\hline 22 & $\ldots$ & & $\ldots$ & $\ldots$ & 14 & 12 & 10 & 8 & 6 & 4 & 2 & & \\
\hline 23 & $\ldots$ & & $\ldots$ & $\ldots$ & & 13 & 11 & 9 & 7 & 5 & 3 & 1 & \\
\hline 24 & $\ldots$ & & $\ldots$ & $\ldots$ & & 14 & 12 & 10 & 8 & 6 & 4 & 2 & \\
\hline 25 & 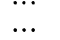 & & $\cdots$ & $\begin{array}{l}\cdots \\
\cdots\end{array}$ & & $\ldots$ & 13 & 11 & 9 & 7 & 5 & 3 & 1 \\
\hline 26 & $\ldots$ & & $\ldots$ & $\ldots$ & & $\ldots$ & 14 & 12 & 10 & 8 & 6 & 4 & 2 \\
\hline 27 & $\ldots$ & & $\ldots$ & $\ldots$ & & $\ldots$ & & 13 & 11 & 9 & 7 & 5 & 3 \\
\hline 28 & $\ldots$ & & $\ldots$ & $\ldots$ & & $\ldots$ & & 14 & 12 & 10 & 8 & 6 & 4 \\
\hline 29 & $\ldots$ & & $\ldots$ & $\ldots$ & & $\ldots$ & & $\ldots$ & 13 & 11 & 9 & 7 & 5 \\
\hline 30 & $\ldots$ & & $\ldots$ & $\ldots$ & & $\ldots$ & & $\ldots$ & 14 & 12 & 10 & 8 & 6 \\
\hline 1 & $\ldots$ & & $\cdots$ & $\ldots$ & & $\ldots$ & & $\ldots$ & $\ldots$ & 13 & 11 & 9 & 7 \\
\hline 2 & $\ldots$ & & $\ldots$ & $\ldots$ & & $\ldots$ & & $\ldots$ & $\ldots$ & 14 & 12 & 10 & 8 \\
\hline 3 & $\ldots$ & & $\ldots$ & $\ldots$ & & $\ldots$ & & $\ldots$ & $\ldots$ & & 13 & 11 & 9 \\
\hline 4 & $\cdots$ & & $\cdots$ & $\ldots$ & & $\ldots$ & & $\ldots$ & $\ldots$ & & 14 & 12 & 10 \\
\hline 5 & $\begin{array}{l}\cdots \\
. .\end{array}$ & & $\begin{array}{l}\cdots \\
\cdots\end{array}$ & $\cdots$ & & $\cdots$ & & $\begin{array}{l}\cdots \\
\cdots\end{array}$ & $\ldots$ & & $\ldots$ & 13 & 11 \\
\hline 6 & $\ldots$ & & $\ldots$ & $\ldots$ & & $\ldots$ & & $\ldots$ & $\ldots$ & & $\ldots$ & 14 & 12 \\
\hline 7 & $\ldots$ & & $\ldots$ & $\ldots$ & & $\ldots$ & & $\ldots$ & $\ldots$ & & $\ldots$ & & 13 \\
\hline 8 & $\ldots$ & & $\ldots$ & $\ldots$ & & $\ldots$ & & $\ldots$ & $\ldots$ & & $\ldots$ & & 14 \\
\hline
\end{tabular}

By these means on any given day a series of dried cords for injection into a patient can be commenced, beginning with a cord which has dried 13 or 14 days, and diminishing by one day of drying each day. It is usual however in Shanghai, where, on account of the short incubation period of street rabies, almost every case is treated by the more intense method, to give on the first day emulsions of cords dried 13, 11 and 9 days respectively, and on the second day those dried 12, 10 and 8 days, the series being rapidly ascended to cords dried 7 days. 


\section{A. Stanley}

In order to allow for contingencies of lengthened incubation, or of failure to contract rabies, an extra rabbit over and above the series is inoculated weekly. Thus the inoculation of some 235 rabbits yearly suffices for the maintenance of the series and for the treatment of at least ten cases a day. It is not necessary for a rabbit to die precisely every second day, for if killed after the symptoms of rabies are developed, the brain is equally virulent, as is also the brain of a rabbit dead of rabies preserved for a few days in ice.

The series of dried cords used in the cases first treated, was the simple one beginning with a cord dried 14 days, followed on each succeeding day by a cord dried a day less. When however the street rabies was found to be of a particularly virulent type it was thought expedient to use a more intensive treatment even for ordinary cases, and the series now employed is given in the following table.

In two cases the injections were, with the happiest results, carried down to cords dried only one day, and in two other cases in which the treatment was commenced 14 days after the bite, the series was started by injecting a 7 day cord.

\section{TABLE V.}

Series of cords used for anti-rabic treatment.

\begin{tabular}{|c|c|c|c|}
\hline \multirow[b]{2}{*}{$\underset{\text { treatment }}{\text { Day of }}$} & \multicolumn{3}{|c|}{ Day of drying of cord } \\
\hline & $\begin{array}{l}\text { For prophylactic } \\
\text { purposes }\end{array}$ & $\begin{array}{c}\text { For small bites on } \\
\text { extremities }\end{array}$ & $\begin{array}{l}\text { For deep bites, bites on } \\
\text { head and face \& where } \\
\text { cases come under treat- } \\
\text { ment late }\end{array}$ \\
\hline $\begin{array}{r}1 \\
2 \\
3 \\
4 \\
5 \\
6 \\
7 \\
8 \\
9 \\
10 \\
11 \\
12 \\
13 \\
14 \\
15 \\
16 \\
17 \\
18 \\
19 \\
20 \\
21\end{array}$ & $\begin{array}{r}14 \\
13 \\
12 \\
11 \\
10 \\
9 \\
8 \\
7 \\
6 \\
5 \\
4 \\
3\end{array}$ & $\begin{array}{rrr}14 & \text { and } & 12 \\
13 & , & 11 \\
10 & , & 8 \\
9 & , & 7 \\
6 & & \\
5 & & \\
4 & & \\
3 & & \\
6 & & \\
5 & & \\
4 & & \\
3 & & \\
4 & & \\
3 & & \end{array}$ & $\begin{array}{cccc}13, & 11 \text { and } 9 \\
12, & 10 \text {, } 8 \\
7 & & \\
6 & & \\
5 & & \\
4 & & & \\
3 & & & \\
6 & & \\
5 & & \\
4 & & \\
3 & & \\
6 & & \\
5 & & \\
4 & & \\
3 & & \\
6 & & \\
5 & & \\
4 & & \\
3 & & \\
4 & & \\
3 & & \end{array}$ \\
\hline
\end{tabular}

Journ. of Hyg. I 
The method used at Kitasato's laboratory in Tokio (where the number of cases is also small, owing to the rarity of rabies in Japan) differs from ours in that emulsions of the cords of different days' drying are made, and kept up to three days in ice for use if called for-e.g. a cord dried say 14 days is made into an emulsion on that day and, kept in ice, may be given three days hence as an emulsion of a 14th day dried cord. I prefer, however, to use freshly prepared emulsions of the dried cord because they undoubtedly become altered by keeping, and freshly prepared emulsions are less liable to contamination by external organisms. I have found that the cords though removed under strict asepsis and manipulated entirely in sterilised vessels, more frequently than not, when inoculated on agar, give rise to bacterial growth. At the Saigon Pasteur Institute cords are dried the requisite number of days to form the series, and preserved in glycerin in sealed tubes. These tubes may be sent through the post, whereby treatment can be carried out at a distance from the mother institution.

\section{Inoculation of Rabbits.}

In the beginning sub-dural inoculation was practised, by cutting down on the bone, reflecting the periosteum and trephining near the middle line at the point where the line joining the posterior margin of the orbits crosses it. The circle of bone having been removed the injection was made with a hypodermic syringe immediately below the dura mater. This method was later replaced by that of intra-cerebral inoculation described by Leclainche and Morel $^{1}$ which has proved simpler and quicker and quite as effective. The hair of the top of the head and between the eyes and ears is cut as short as possible with scissors. The animal is fixed on a rabbit board having a mouth-piece and the shaved portion is sterilised with a $10 \%$ solution of lysol in alcohol, which is allowed to remain on for a quarter of an hour. No anæsthetic is given, as it was found that very little pain was inflicted. No sign of pain was given by the animal except when, at the end of the operation, sutures were passed to draw the edges of the skin incisions together. The suturing has been replaced by merely approximating the edges of the skin incision with collodion, and, apart from the discomfort of being fixed on the board in an unnatural position I am of opinion that very little pain is inflicted. The skin, which is very thin, is incised to the bone for a distance of $1.5 \mathrm{~cm}$. about $2 \mathrm{~mm}$. from the median line, the middle of the incision being on a line joining the posterior margins of the orbits. The periosteum is reflected from an area of bone sufficiently large to permit of the application of a drill $2 \mathrm{~mm}$. in diameter. A minute hole is made in the cranium just large enough for the passage of a hypodermic needle. The needle is thrust gently in a direction forwards and outwards to the depth of

\footnotetext{
1 Ann. de l'Inst. Pasteur, 1899, vol. xIII., p. 513.
} 
$1 \mathrm{~cm}$. and $0 \cdot 1$ c.c. (about 2 drops) of emulsion is injected. If much more than this is injected the rabbit dies with Jacksonian convulsions, contractures and coma. The periosteum is now replaced over the point of entrance to the brain cavity, and the skin surfaces apposed and sealed together with collodion. If this seal is imperfect, and the escape of cerebro-spinal fluid permitted, the animal usually dies on the following day. The effectual sealing of the wound is important. The rabbit is now marked with the day of the month on its back with a solution of fuchsin in alcohol and the particulars of source of virus and date of inoculation entered on a sheet suspended over the hutches where the inoculated rabbits are kept.

The virus for inoculation of the rabbits is prepared by taking a fragment of the bulb of the preceding rabbit dead of intensive rabies and grinding it to a cream in a small porcelain mortar, sterilised by boiling in plain water. Any fibrous piâmater is removed. A few drops of sterile normal saline is added to make the emulsion of such a consistency as can be taken up by a hypodermic syringe. The kind of hypodermic syringe is of some importance, and the only one which has given complete satisfaction, by being easily sterilisable by boiling and never getting out of order, is the all-metal one with a steel piston and platino-iridium needles. The steel piston requires lubrication, sterile castor-oil being used. By these means rabbits rarely die of anything but rabies after the operation, and very seldom does rabies fail to supervene.

\section{Preparation of Cords for Use in Anti-rabic Treatment.}

The inoculated rabbits begin to show symptoms of rabies on the sixth to eighth day, refusing food, and hanging down the head. They are sometimes excitable, the stage of excitation being followed by paralysis of the limbs, the onset of which can be most easily tested by the strength with which a lateral push is resisted. Finally the limbs give way, the animal lies helpless and there is usually diarrhoea.

The dead rabbit is placed on a galvanised iron tray and its legs tied to rings at the four corners. The head and back are sterilised by alcoholic lysol $(10 \%)$ allowed to remain on for half an hour. The instruments necessary are sterilised by boiling in plain water, namely, three sets of forceps and scalpels, with scissors and bone-forceps angled on the flat. The skin is first reflected and then the cranium and vertebral column are freed from muscle. With bone-forceps, working from behind forwards, the cord and brain are exposed by cutting through the bony casing alternately on either side. The cord is raised from its bed by passing the end of the blunt-pointed scissors rapidly along each side so as to detach the spinal nerve junctions. A fine silk ligature is passed round the cord in the lower dorsal region and the cord cut through at this point and near the bulb, so as to leave a length of about $10 \mathrm{~cm}$. hanging from the ligature. This is suspended in an ordinary narrowmouthed stoppered bottle which has been sterilized and contains some freshly dehydrated caustic potash, soda or calcium chloride. The silk ligature passes out between the stopper and the neck of the bottle and by this it is manipulated. The date on which the cord is placed in the drying bottle is marked clearly by means of alcoholic fuchsin with a brush on the outside of the bottle. This is then placed 
in a dark incubator provided with a capsule regulator, the temperature being kept constantly at $23^{\circ} \mathrm{C}$. by means of hot water in winter and ice in summer. The apparatus used by me was made by Hearson, and, though the details of workmanship are careless, the regulator works well.

To prepare the emulsion of the cord for anti-rabic treatment $1 \mathrm{~cm}$. of cord is cut off and triturated dry in a small porcelain mortar such as can be conveniently boiled bottom upwards in a small steriliser. When completely broken up 5 c.c. of sterile normal salt solution are added, and a fine emulsion made by the pestle. The dose of this is 1 c.c., the equivalent of $2 \mathrm{~mm}$. of cord. 